\title{
Quine e o pluralismo lógico
}

Quine and logical pluralism

\section{Alberto Leopoldo Batista Neto ${ }^{1}$}

\author{
1 Doutorado em Programa de Doutorado Integrado em Filosofia pela Universidade Federal da Paraíba, Brasil. Professor substituto da Universidade \\ do Estado do Rio Grande do Norte, Brasil. \\ E-mail: albertolbneto@yahoo.com.br . Orcid: http://orcid.org/0000-0002-3070-7934
}

Resumo: Investiga-se a possibilidade de uma abordagem do fenômeno do pluralismo lógico a partir de uma perspectiva inspirada no pensamento de Quine. A matematização da lógica termina por levar à flexibilização da teoria lógica, logo surgindo, não apenas sistemas complementares e alternativos à lógica clássica, mas também a questão da admissibilidade de mais do que um sistema lógico. A tal posição se dá o nome "pluralismo lógico”. Quine foi um destacado defensor da lógica clássica a partir de uma perspectiva monista, ainda que admitisse em princípio a possibilidade de sua revisão. Pode-se, contudo, investigar se as linhas gerais do pensamento quineano são compatíveis com uma perspectiva pluralista. Algumas possibilidades são levantadas tomando em consideração propostas como as teorias pluralistas de Carlo Dalla Pozza e Richard Epstein. Conclui-se que, embora Quine não concebesse a possibilidade de apoiar o pluralismo lógico, a sua filosofia ajuda a enquadrar e avaliar as maneiras de estudar o assunto.

Palavras-chave: W. V. O Quine (1908-2000), revisabilidade lógica, pluralismo lógico.

ABSTRACT: We investigate the possibility of na approach to the phenomenon of logical pluralismo from a perspective inspired by the thougt of Quine. The mathematization of logic ends up leading to the flexibilization of logical theory, so that soon are seen to rise, not only systems complementary and alternative to classical logic, but also the question of the admissibility of more than one logical system. This thesis is termed "logical pluralism". Quine was a distinguished defender of classical logic from a monistic perspective, even while admitting in principle its revisability. One might, though, investigate if the general lines of Quine's thought are compatible with a pluralistic perspective. Some such possibilities are raised by taking into account the pluralist theories of Carlo Dalla Pozza and Richard Epstein. It is concluded that, although Quine did not conceive of the possibility of endorsing logical pluralismo, his philosophy helps in framing and evaluating the attempts to understand this issue.

Keywords: W. V. O Quine (1908-2000), logical revisability, logical pluralism.

\section{Introdução}

Com a matematização da lógica, criou-se espaço para o surgimento de múltiplos sistemas lógicos, complementares ou alternativos àquele que veio a chamar-se "lógica clássica". A aceitação de uma pluralidade de sistemas lógicos como igualmente adequados é a tese central do pluralismo lógico, do qual se procura oferecer uma justificação. É possível defender uma versão do pluralismo lógico inspirada no pensamento do filósofo norte-americano Willard Van Orman Quine (1908-2000), apesar de sua expressa oposição a tal 
projeto. A partir da origem histórica da problemática, serão apresentadas a questão do pluralismo e as distinções conceituais apropriadas; a seguir serão expostas as críticas dirigidas por Quine à tese pluralista, embora situadas em seu contexto teórico amplo, o qual, conforme será sugerido, oferece suporte, desde que se tomem as precauções conceituais exigidas, a uma fundamentação de uma postura pluralista; por fim, seguindo as sugestões de Antonio Negro, argumentar-se-á em favor da tese referida. Obtém-se que, com o auxílio de aparatos formais como aqueles desenvolvidos por Carlo Dalla Pozza e Richard Epstein, uma via promissora é aberta a tal intento, do que se conclui uma surpreendente fecundidade do pensamento quineano, ainda que os resultados não sejam conclusivos.

\section{Surgimento e colocação do problema do pluralismo}

A matematização da Lógica é um fato consumado na organização acadêmica atual dos estudos da disciplina. Prenunciada por Leibniz, tornou-se parte constitutiva do trabalho dos algebristas ingleses do século XIX (Boole, De Morgan), sendo depois conduzida, principalmente por Frege, a plena maturidade.

Frege pretendia dar à sua lógica um estatuto universal. De fato, o que ensejava não era uma simples matematização de princípios do raciocínio válido, mas codificar uma nova e abrangente noção dos princípios que governam o domínio objetivo do verdadeiro e do falso (o alcance do "pensamento", entendido não em sentido psicológico, mas como realidade autônoma capaz de ser apreendida, reconhecida e asserida, sem identificar-se a nenhuma dessas operações ou constituir-se por elas). Nesse ponto, Frege destaca-se da tradição algébrica dos lógicos britânicos. Sua intenção primária era desenvolver uma versão suficientemente compreensiva e clara do conceito de analiticidade para enfrentar a tese kantiana de que a matemática (no caso visado por Frege, especificamente a aritmética) é constituída por um corpo de verdades sintéticas a priori, mostrando-a constituída por verdades analíticas, num sentido preciso, derivadas estritamente das leis da Lógica. O mesmo projeto, batizado "logicismo", foi assumido, e estendido para a totalidade da Matemática por Russell e Whitehead, que, portanto, mantinham a consideração do escopo universal da lógica que ajudavam a desenvolver (embora a constatação do uso de princípios dubiamente "lógicos" como o axioma da redutibilidade e o do infinito por Russell e Whitehead tenha tolhido ao seu programa substancial parcela de credibilidade) - (v. POTTER, 2008, p. 43-55; SILVA, 2007, p. 123-136).

O projeto envolvia a reforma da lógica, disciplina que então se considerava em larga medida restrita à teoria dos silogismos de Aristóteles (além das chamadas "inferências imediatas" - base da teoria da conversão das proposições), e pela lógica proposicional dos "silogismos hipotéticos" (termo que recebia compreensão bastante mais ampla que o da regra homônima, admitida nos sistemas modernos), que lida com conjunções, disjunções e condicionais (não obstante os manuais de "lógica" incluírem muito de indução destacando a tradição que vai de Francis Bacon a John Stuart Mill -, e metodologia científica em geral, em regra reunida sob o título de "lógica material" - por oposição à lógica formal - ou "lógica maior", por fornecer o material das premissas maiores dos silogismos). A consciência de que o coração da Lógica se encontrava nas teorias aristotélicas da proposição e do raciocínio dedutivo revela-se na célebre declaração de Kant (tão frequentemente citada, mesmo a título de gracejo, nos manuais modernos), de que a lógica nascera essencialmente completa com os textos aristotélicos, sendo que posteriores enriquecimentos em nada lhe teriam alterado a substância. Muitas críticas feitas, a partir da perspectiva da lógica moderna, à lógica tradicional, são conhecidas: não somente a silogística aristotélica é um esquema de lógica formal incompleto (por exemplo, restringindo-se a um artificial sistema triádico - premissa maior, premissa menor, conclusão 
- e excluindo como estrangeira a lógica proposicional - havendo como duas "lógicas" não comunicantes), mas também legitima inferências duvidosas, devido à suposição existencial atrelada às proposições categóricas universais, cuja aceitação pode acabar levando a incoerências. Também a forma sujeito/cópula/predicado (incrementada por quantidade - universal ou particular - e qualidade - afirmação ou negação -, atribuídas, respectivamente, ao termo sujeito e à cópula) mostra-se demasiado restritiva (sufocando, por exemplo, o desenvolvimento de uma lógica das relações) e dificultosa (por converter o que seriam meras categorias gramaticais - sujeito, predicado - em categorias lógicas). Além do mais, o acréscimo das modalidades (necessidade, possibilidade, contingência) parece resultar em novas (e mais complexas) dificuldades e inconsistências (v. KNEALE; KNEALE, 1971, p. 58-61, 86). A nova lógica, integrando em seu seio, como num todo organicamente articulado, um tratamento para a quantificação e para as inferências proposicionais, parecia evitar admiravelmente tais problemas, e não tardou a suplantar a antiga.

Desde o início do desenvolvimento da nova lógica, porém, as abordagens heterodoxas (em relação ao sistema derivado dos trabalhos de Frege, Russell e Whitehead) se multiplicaram, e de tal modo se diversificaram em tempos mais recentes os sistemas não clássicos, que um mapeamento dos sistemas existentes seria uma tarefa verdadeiramente hercúlea, se absolutamente factível. Com efeito, a liberdade para criar novas "lógicas" parece não conhecer limite. Inicialmente propostos para preencher lacunas deixadas pelo ferramental clássico, ou apresentar-se como seus rivais, prosperou grandemente o estudo das propriedades formais dos diversos sistemas (ou suas diversas apresentações, supondo que apresentações diversas são capazes de referir-se a um só e mesmo sistema lógico), normalmente auxiliado por instrumentos matemáticos, e não raro desenvolvido a partir de analogias estruturais com certos domínios da matemática. A opulenta profusão de lógicas presente na literatura técnica não produziu senão incipiente impacto na produção filosófica. As possíveis revisões da lógica padrão para atender a desiderata teóricos específicos chegam a ser apresentados como o cerne da lógica filosófica (v. BURGESS, 2009, p. vii; também PRIEST, 2001, p. xvii; DA COSTA, 1980, p. 28-58). A oportunidade e desejabilidade de semelhantes revisões é tópico de intenso debate nas últimas décadas, mas quase sempre, ao menos no que se refere às denominadas lógicas alternativas (i.e., aquelas em que princípios e esquemas inferenciais "classicamente" tidos por válidos deixam de possuir aplicabilidade geral), tal debate muito tendeu a concentrar-se sobre uma eventual mudança global de cânones reguladores da racionalidade (v. HAACK, 1978, p. 207-227), o que ocasionou certa desconfiança, frente às iniciativas heterodoxas, dos filósofos treinados (frequentemente não além de um nível elementar) sob os cânones da lógica clássica.

A matematização da lógica, contudo, conferia uma considerável flexibilidade ao aparato lógico disponível. Cedo, dificuldades com a interpretação do operador condicional ("implicação material”) levariam C. I. Lewis a desenvolver o sistema da implicação estrita, germe da moderna lógica modal (problemas sobre o condicional levarão, ainda, ao desenvolvimento das lógicas relevantes e muitas outras tentativas de elaboração de ferramentas lógicas específicas para tratar o condicional, seja em sua versão indicativa, seja na contrafactual). Considerações sobre alguns trechos de textos de Aristóteles conduziriam J. Lukasiewicz a desenvolver as lógicas polivalentes (às quais chegou, paralelamente, por diversa motivação - mais estritamente matemática - Post). Discussões sobre a epistemologia da Matemática levaram ao desenvolvimento, por Heyting, da lógica intuicionista - partindo da aritmética intuicionista de Brouwer (v. DA COSTA, 1980, loc. cit; MALINOWSKI, 1993; KNEALE; KNEALE, 1971, 513-575) - depois defendida por Dummett como tendo alcance geral (DUMMETT, 1978). Aspectos do raciocínio com tempos verbais levaram autores como Prior a propor a ideia de "lógica temporal". Desenvolvimentos posteriores no campo da lógica modal sugeriam um caminho para o disciplinamento lógico das noções de necessidade, possibilidade, predicado 
essencial etc., dando origem a pujante tendência especulativa: a metafísica dos mundos possíveis. Discussões sobre a caracterização dos "mundos", a relação de acessibilidade entre eles, os critérios de "identidade transmundana" etc. conduziram ainda a novos desenvolvimentos formais. Além disso, os sistemas modais prestavam-se à codificação dos princípios reguladores de outros pares conceituais, tais como obrigação e permissão (lógica deôntica), conhecimento e crença (lógica epistêmica), demonstrabilidade e consistência (lógica da demonstrabilidade - provability) etc. O persistente problema dos paradoxos lógicos e semânticos (além de certa herança da dialética hegeliana e marxista) inspirou a criação dos sistemas em que as contradições não conduzem à trivialização (paraconsistentes). Aqui também se incluem os sistemas de lógica relevante (ou "da relevância"), embora motivados pela constatação do que se chamou "paradoxos da implicação material"; restrições sobre recursos a serem usados em uma dedução levaram à elaboração da lógica linear; considerações sobre vaguidade conduziram à lógica furæyy. (v. PRIEST, 2001; BURGESS, 2009).

Não se tardou a perceber que o procedimento poderia se estender nas mais diversas direções. Newton da Costa, reconhecendo que, mesmo no quadrante clássico, se impõe uma arbitragem acerca da "grande lógica" (que deve suplementar a chamada "lógica elementar" na maioria dos contextos relevantes) - podendo-se escolher, digamos, entre uma versão da teoria dos tipos de inspiração russelliana, uma das variantes (não equivalentes) da teoria de conjuntos, ou a teoria de categorias [não confundir com a noção aristotélica] -, argumenta que, conquanto a razão se constranja, constitucionalmente, à opção por uma lógica uniforme em cada contexto de operação, o derradeiro critério para a escolha efetiva em um dado contexto é pragmático, e nenhuma característica a priori, quer na ordem da razão, quer na ordem da realidade, inclina a decisão necessariamente no sentido da lógica clássica (v. DA COSTA, 1980, p. 132-165). Os próprios princípios que definem tradicionalmente a lógica clássica - os célebres princípios ditos aristotélicos de identidade, de não contradição e do terceiro excluído - convertem-se em fórmulas (na medida em que se julga poder interpretálas como representando tais princípios) que não gozam, em relação às demais, de qualquer privilégio destacável.

A situação atual da lógica terminou por conduzir à admissão, por vários autores, de alguma versão de pluralismo lógico (v. BEALL \& RESTALL, 2006; NEGRO, 2010): não haveria apenas uma lógica correta (tese monista), mas muitas. O critério de aceitabilidade de um sistema formal (que pode ser apresentado de diversas maneiras: como uma classe de teoremas, como $n$-uplas de fórmulas que determinam uma relação de consequência - sintática ou semântica, com uma ou múltiplas consequências -, como sistemas de Hilbert, de dedução natural, de tableaux, de cálculo de sequentes, de semânticas kripkeanas etc.) para ser classificado como "lógica" tende a variar em conformidade com a perspectiva adotada. Beall e Restall defendem que, para ser uma lógica, um sistema entendido como linguagem formal interpretada deve preencher requisitos apropriados de necessidade, formalidade e normatividade, definindo-se ainda relativamente a uma noção adequada de casos (que podem ser modelos, mundos possíveis, situações ou estágios num processo de construção ou verificação). Algumas, ainda, darão à lógica clássica um estatuto diferenciado e, em certo sentido, prioritário (tal é o caso das lógicas de Epstein e do pluralismo global de Dalla Pozza). É comum, igualmente, exigir que as lógicas contempladas sejam de algum modo compatíveis entre si, de modo a não permitir, por exemplo, inferir como verdadeira, de um mesmo conjunto consistente de premissas, conclusões mutuamente contraditórias (p.ex. Dalla Pozza e Beall \& Restall). Outras perspectivas, porém, serão mais liberais. A lógica universal, defendida por Béziau (cujas origens identifica, porém, em Tarski e Paul Hertz, ainda na década de 1920), procura caracterizar uma lógica segundo uma dada relação de consequência (definida a partir de estruturas variáveis), sobre a qual não se impõem, a princípio, quaisquer restrições. Isso permite comparar sistemas de lógica, considerar traduções entre eles, "reparti-los" em subsistemas, combiná-los em 
sistemas maiores (com efeito, o tópico da análise e síntese de sistemas lógicos - splitting e splicing - tem recebido considerável atenção na literatura) etc., atividades que são desempenhadas por lógicos profissionais já desde as primeiras décadas do século XX, e que constituem parte integral do modus investigandi daquela comunidade científica (v. BEALL \& RESTALL, 2006; NEGRO, 2010; BÉZIAU, 2006; CARNIELLI et al., 2008).

Uma vez admitida a legitimidade simultânea de múltiplos sistemas lógicos segundo variadas compreensões acerca dos princípios que regulam o que é ser uma lógica, há ainda vários sentidos em que é possível ser pluralista: pode-se ser um pluralista global, defendendo que as diferentes lógicas atentam a diferentes aspectos dos raciocínios, mas que, ao menos em princípio, estendem-se irrestritamente a diferentes contextos e áreas teóricas (embora uma determinada lógica possa ser em regra mais oportuna para uma zona discursiva, e fundamentalmente inútil para outra); pode-se ser um pluralista local, afirmando que há lógicas determinadas para campos determinados da realidade (a aplicação da lógica a fenômenos quânticos, por exemplo, levaria à falha da lei de distributividade); e pode-se ainda ser um instrumentalista (posição já preconizada, ao se associar a seu relativismo linguístico fundado num princípio de tolerância, por Carnap [1937, 51-52]), reconhecendo que o emprego desta ou daquela lógica deve ser determinado pelo contexto concreto de aplicação, sem que algo na própria ordem das coisas, ou na essência mesma da lógica o imponha. Há certa resistência à aceitação do instrumentalismo, embora este pareça naturalmente melhor adaptado às práticas profissionais dos lógicos hodiernos: provavelmente porque os filósofos, na tradição analítica, sentem necessidade de um referencial estável para a concepção de racionalidade que subjaz a suas teorias. O próprio Quine não podia comungar de tal perspectiva, uma vez que, para ele, longe de ser um mero instrumento adaptado para uma diversidade de tarefas, a lógica (univocamente entendida) desempenha um papel central no estabelecimento da rede de crenças que forma o corpo da ciência, como visão integral da realidade (QUINE, 1951, p. 42-46; 1986, 80-81; NEGRO, 2010, p. 22). O pluralismo local, por sua vez, pode esbarrar na resistência à admissão de que a lógica possa sofrer restrições em conformidade com o assunto tratado, comprometendo a neutralidade tópica, amiúde apresentada como característica altamente desejável (senão absolutamente essencial) para um candidato ao posto de "lógica" (v. MACFARLANE, 2000, 69-78)

\section{Quine entre monismo e pluralismo lógico}

Quine figura de forma especialmente notável como defensor de uma interpretação unitária da lógica, combatendo as diversas propostas de revisões sobre o que, desde as primeiras décadas do século XX, se admite chamar lógica "clássica" (cálculo proposicional e cálculo de predicados de primeira ordem), embora se sustentando em argumentos pragmáticos, e aceitando, em princípio, a possibilidade da revisão das leis da lógica. Se tal revisão é, por si, perfeitamente lícita, contudo, não segue que seja oportuna. A revisabilidade da lógica se coaduna com o caráter holístico da compreensão quineana do conhecimento, e está vinculada à sua célebre crítica da noção de analiticidade. Não havendo uma linha de demarcação claramente traçada que permita separar enunciados entre dependentes e não dependentes da experiência, e não havendo possibilidade de testar afirmações isoladamente do restante do organismo teórico de que fazem parte - i.e., a rigor, da totalidade da Ciência -, pode-se, no máximo, dizer que os princípios lógicos estão situados menos às margens do sistema do conhecimento (aquele setor mais particularmente sensível à experiência e menos consolidado pelas práticas cognitivas - portanto, de revisão admitidamente menos problemática, dado o estágio corrente das investigações científicas) e, por conseguinte, gozam de solidez relativamente maior do 
que a daquelas afirmações geralmente tidas na conta de mais "empíricas” (v. QUINE, 1951, 42-46).

Mesmo essencialmente revisáveis, as leis da lógica, para Quine, contam com posição privilegiada, podendo ser classificadas como "analíticas por estímulo" (stimulus analytic) - com efeito, uma noção de analiticidade que se restringisse estritamente aos cânones lógicos sequer estaria enredada, para Quine, nas mesmas dificuldades que afetam outras tentativas de defini-la, por exemplo pelo apelo a um conceito como o de sinonímia (v. QUINE, 1951, p. 23-24) -, constituindo-se em disposições estáveis para o assentimento ou a denegação apreensíveis por indução sobre os comportamentos linguísticos das várias sociedades humanas. As "funções de veredito" (verdict functions) dariam naturalmente origem às tabelas de verdade. De tal modo o sentido destas estaria, então, assentado, que a ideia de reinterpretar uma constante lógica, dando origem, por exemplo, aos conectivos não-clássicos, equivaleria, antes que a uma mudança de lógica, a uma mudança de assunto, conforme a célebre formulação do próprio Quine (v. QUINE, 1960, p. 52-55; 1970, p. 80-81; BERGER, 1980; NEGRO, 2010, p. 19-22).

Além do mais, o projeto filosófico quineano, à busca de estabelecer um arcabouço lógico-conceitual para a ciência que atenda a determinados requisitos de clareza conceitual, uniformidade e simplicidade, ainda que procurando conservar suficiente flexibilidade para comportar os vários universos de discurso das disciplinas científicas sem recorrer a reducionismos "fundacionais" (que terminariam por prejudicar a satisfação das condições anteriores), combina a liberalidade na recepção de diferentes ontologias (princípio de relatividade ontológica) a uma rigorosa austeridade na escolha do aparato formal. O uso de vocabulário intensional é vetado com a mesma presteza com que se rejeitam acepções distintas de existência, que implicariam, mais uma vez, mudança de lógica e, com ela, perda em inteligibilidade ${ }^{1}$. A compreensão quineana da existência, portanto, é unívoca, mas as afetivas atribuições de existência são sempre relativas a sistemas de coordenadas ou teorias de fundo previamente adotadas, que supõem recurso particular a dada linguagem, em cujo uso se encontram implícitos os compromissos sobre o que se toma por existente. Em outras palavras, a questão sobre "o que há" sempre é mediada pelo que "dizemos que há”. O que dizemos que há, por sua vez, depende sempre de um arcabouço linguístico que nunca é capaz de fixar, de uma vez para sempre, um domínio de referência, uma vez que, para o mesmo domínio de dados observáveis, é sempre possível propor descrições alternativas e igualmente adequadas, com diferentes critérios de individuação (inescrutabilidade da referência). Entretanto, além da estabilidade dos padrões de assentimento e dissentimento que constituem a base da interpretação das constantes lógicas, deve-se admitir o critério de existência relacionado com uma interpretação objetual e unívoca do quantificador existencial, para não mencionar o caráter holístico das escolhas teóricas, concorde que se supõe ser com a melhor ordenação do conhecimento científico disponível (v. QUINE, 1948; 1951; 1960, p. 23-72, 175-213; 1968; ALVES, 2014).

Em conformidade com essa visão holística, quando Quine pensava no assunto das lógicas não-clássicas, tinha em vista a possibilidade de uma revisão global dos princípios da lógica, que deveriam constituir um enquadramento único. De fato, boa parte da discussão acerca das lógicas não-clássicas, até tempos recentes, concentrava-se na eventualidade de uma tal revisão universal - e sua admissibilidade (v. HAACK, 1978, loc. cit.). A ideia de que a lógica, ela mesma, pudesse vir a ser relativizada, e que fosse aceitável a

\footnotetext{
1 Mais tarde, em The Roots of Reference (1973), Quine atenuará essa posição: reconhecendo o caráter não exaustivo das "tabelas de veredito" para determinação dos valores de verdade de sentenças compostas, uma vez que se admita, ao lado das possibilidades de assentimento e denegação, aquela da suspensão de juízo, abre-se espaço para tornar aceitável, como resultado da indução sobre o comportamento linguístico das comunidades, além das tabelas de verdade clássicas, também as intuicionistas - donde resulta uma fundamental indeterminação a respeito da escolha efetiva.
} 
convivência conjunta dos múltiplos sistemas (não só na produção técnica dos lógicos, mas ainda numa visão compreensiva da própria racionalidade) ganhou corpo e angariou apoio substancial somente nas últimas décadas. Em sua dissertação sobre Quine e o pluralismo lógico, Antonio Negro (2010, p. 11-12) afirma haver duas formas básicas de conflito entre lógicas: o conflito genuíno e o conflito parcial. No primeiro caso, assume-se uma divergência real entre dois sistemas rivais como formas reciprocamente incompatíveis de interpretar, digamos, uma determinada constante lógica (como um conectivo ou quantificador), cada uma das quais se propondo como a interpretação correta. Neste caso, há uma verdadeira oposição entre os sistemas, pois divergem no modo de tratar um mesmo assunto, tido por externo e anterior a ambos. No caso do conflito parcial, assume-se que os sistemas em conflito lidam com objetos diferentes, definidos pelas funções que desempenham nos respectivos sistemas. Assim, uma "conjunção", tal como aparece em um dos sistemas, significa algo efetivamente distinto da "conjunção" que aparece em outro (sendo a homonímia entre elas fundada numa leitura equívoca ou, na melhor das hipóteses, analógica, como quer que se entenda este conceito), nenhuma das quais se apresenta como a leitura correta do que seria a conjunção extra ou préteórica. As razões para rejeitar um sistema em benefício do outro devem ser aqui, principalmente, pragmáticas, dizendo respeito antes à aptidão geral de cada sistema no disciplinamento de uma região do discurso que à propriedade da sua interpretação particular desta ou daquela expressão (como, no exemplo proposto, a conjunção).

Quine rejeita, por princípio, o primeiro tipo de conflito. Sua tese de que mudança de lógica acarreta mudança de significado inviabiliza a admissão de uma divergência real entre duas supostas interpretações para o mesmo conceito lógico. Além do mais, o pensamento de Quine é constitutivamente avesso à ideia de uma realidade exterior à conceitualização teórica: não haveria um parâmetro objetivo e exclusivo a que se poderia esperar que uma lógica se ajustasse. Quanto ao conflito parcial, Quine admite sua possibilidade, conquanto duvide que seja oportuna. Considerando a lógica clássica um arcabouço racional suficientemente bem sucedido para estruturar o corpo da ciência (juízo que deve se fundamentar nos modelos de reconstrução racional iniciados pelos positivistas lógicos e que inspiram o próprio projeto quineano), sua substituição por sistemas alternativos tenderia a violar um princípio de mutilação mínima - além de ser especialmente onerosa, considerado o esforço geral que dela se depreenderia (v. NEGRO, 2010, p. 13-18). Além do mais, a visão de Quine sobre ontologia, que vincula sua defesa da noção de compromisso ontológico a uma teoria clássica da quantificação (livre, ainda, de contextos intensionais), reforça sua posição (v. ALVES, 2014).

Pode-se perguntar, então, em que medida as posições de Quine são defensáveis, e se não é possível a admissão de uma visão (coerente e praticável) da lógica que se abra à aceitação de muitas lógicas, ao invés de uma. A defesa quineana da unicidade da lógica parece estar diretamente relacionada à sua crença na unidade da ciência (além de seu naturalismo filosófico - que atribui à ciência o monopólio da empreitada cognitiva). A unificação dos saberes científicos em um bloco que somente em sua integridade é passível de ser posto efetivamente à prova, dotado de uma compreensão unívoca da existência das entidades admitidas, unido por uma racionalidade sólida, simples e eficiente, já consagrada pelos precursores filosóficos imediatos do próprio Quine, é um motivo forte para sua defesa do monismo lógico - e para a eleição da lógica clássica como sistema a preferir. Uma vez assumida a posição monista, a noção de conflito parcial entre lógicas implica a necessidade de optar por um sistema de lógica em detrimento de todos os demais, mesmo que, a rigor, eles não se encontrem em conflito genuíno (v. NEGRO, 2010, p. 14-18). Além disso, a escolha dos parâmetros clássicos é justificada por Quine não como uma herança filosófica recente, mas (pelo menos no que concerne à parte proposicional da lógica) como resultado de uma espécie de indução sobre as práticas linguísticas, que gerariam as "tabelas de veredito" como interpretação dos conectivos (v. BERGER, 1980; 
QUINE, 1973, p. 45-49, 75-78).

É possível, contudo, duvidar, quer seja da fundamental unidade do inquérito científico (ou mesmo de suas possíveis reconstruções racionais), quer seja da possibilidade de que um sistema de lógica seja capaz de realizá-la, quer ainda das premissas naturalistas do pensamento quineano, atribuindo importância gnosiológica a outros modos de discurso e apreensão - os quais poderiam, ademais, obedecer a ordenamentos lógico-racionais divergentes.

Também a alegação de Quine de que a indução sobre as práticas linguísticas termina por consolidar os princípios lógicos que tem em mente, é, por si, bastante discutível. A interpretação dos conectivos, tal como apresentada pelas tabelas de verdade para a lógica clássica (ou mesmo para a intuicionista), embora possa primar pela simplicidade, é bastante controvertida, não raro mesmo sendo apresentada como arbitrária - o que é bastante claro, por exemplo, nas discussões sobre o condicional, mas também se aplica a casos como os da conjunção, da disjunção, e da própria negação. A própria ideia de que há algo de recursivamente encontrável nos usos linguísticos correntes que possa ser isolado, por abstração, como um conectivo verofuncional, é coisa duvidosa. Quine argumenta que, em contato com uma comunidade linguística alienígena, um pesquisador que assumisse uma interpretação clássica de um conectivo - digamos, a conjunção - somente traduziria por este conectivo uma partícula que obedecesse às mesmas condições de uso (v. QUINE, 1960, p. 52-55; BERGER, 1980; NEGRO, 2010, p. 30). Porém, é questionável se um pesquisador "típico" - sem qualquer treinamento em lógica matemática - teria tal interpretação do conectivo, para começar. Ademais, é discutível que semelhante método, se de todo viável, é o meio adequado para a determinação dos princípios lógicos: estes foram identificados, empregues e eventualmente justificados no contexto das práticas comunicativas de determinadas comunidades de investigação (filósofos e teólogos, no caso da lógica tradicional; matemáticos e filósofos no caso da lógica moderna) - não havendo a princípio qualquer evidência de que o seu sentido pode ser estendido a práticas dos mais variados grupos humanos, nas muitas circunstâncias que as condicionam (ou mesmo que estas práticas sejam passíveis de um disciplinamento lógico análogo ao que se operou naqueles casos). A proliferação das lógicas não-clássicas, outrossim, é um fato incontornável, que constitui em enorme medida a agenda científica da comunidade dos lógicos. Diante da multiplicidade dos sistemas de lógica, e da própria diversidade da apresentação de tais sistemas, torna-se problemática a identificação das fronteiras da disciplina, assim como a extensão e a compreensão do conceito mesmo de "lógica".

Parece, portanto, haver razões para aceitar alguma versão do pluralismo lógico. Porém, como argumenta Negro, pode-se fazê-lo sem abandonar a tese quineana da mudança de significado decorrente da mudança de lógica, que está no núcleo da sua defesa da lógica clássica como a lógica correta, ou exclusivamente mais adequada. E apresenta o Pluralismo Global de Dalla Pozza (2002) como uma via para fazê-lo: sem comprometer um núcleo comum, evitando um relativismo acerca da verdade (um desideratum estabelecido por Negro para o êxito de uma abordagem pluralista - e que seria posto em risco, segundo ele, por uma abordagem como a de Beall \& Restall (2006) e sem violar o requisito de neutralidade tópica, a distinção estabelecida por Dalla Pozza entre a fórmula radical e o modo pragmático (algo semelhante a uma distinção de atos ilocucionários), esta abordagem reconhece que a mudança de lógica implica mudança de sentido, mas estabelece um meio de impedir que a mudança de lógica acarrete perda de inteligibilidade. A abordagem de Dalla Pozza, portanto, admite uma pluralidade de sistemas lógicos "conflitantes" em sentido parcial, de modo que há, com efeito, uma mudança de significado para as expressões lógicas relevantes (como os conectivos), mas de uma forma que não degenera em pura equivocidade, mas constitui-se numa forma de uso analógico das expressões, que encontram naquele da lógica clássica o seu primum analogatum. Há, portanto, de 
fato uma mudança de assunto, porém uma mudança de assunto controlada por uma transição para diferentes contextos pragmáticos, sem perder de vista uma unidade essencial (ainda que analogicamente fundada) do empenho cognitivo (v. NEGRO, 2010, p. 50-63).

Outra tentativa no mesmo sentido, que também apresenta notável sensibilidade aos requisitos quineanos, é aquela apresentada por Richard L. Epstein (2001). Seu projeto, intitulado The Semantic Foundations of Logic, pretende estabelecer um arcabouço conceitual e técnico para a apresentação de sistemas lógicos em conformidade com alguns princípios considerados muito gerais, como a chamada assunção fregeana (segundo a qual o valor de verdade de uma proposição determina-se pela sua forma e pelas propriedades semânticas de suas partes componentes) e a divisão de forma e conteúdo (que atesta serem semanticamente indistinguíveis proposições dotadas das mesmas propriedades semânticas - uma vez que se definam tais propriedades). Uma lógica pode ser definida, quer como conjunto dado de proposições, quer ainda como relação de consequência, com um enfoque que pode ser sintático ou semântico, embora o autor aponte a dimensão semântica (derivada, conforme pensa, de práticas linguísticas concretas) como de alguma forma prioritária e determinante. O aporte de Epstein permite situar a lógica clássica como ponto de partida, justificando seu caráter de classicidade por considerações de simplicidade e de "universalidade" (ou ausência de especificações contextuais), sendo que as demais lógicas seriam obtidas por acréscimos de conteúdo que representam, em certo sentido, restrições de escopo. Substituindo a ideia quineana de um sentido atribuído às constantes lógicas com base na indução sobre práticas linguísticas pela mais flexível noção de um "acordo" originário a respeito dos princípios que regulam os raciocínios quando determinados aspectos de uma proposição são levados em conta, Epstein reconhece a tese da mudança de lógica como "mudança de assunto", e ainda consegue preservar o caráter fundamental da lógica clássica como aquela em que o requisito da neutralidade tópica é mantido de forma mais rigorosa. Similarmente, portanto, à proposta de Dalla Pozza, a de Epstein assume um núcleo original clássico que faz com que as mudanças de sentido assimiladas não se percam na pura equivocidade.

Ambas as propostas, de Dalla Pozza e de Epstein, não somente compartilham a compreensão quineana de que a "mudança de lógica é uma mudança de assunto", admitindo a pluralidade de lógicas pela introdução de critérios determinados de "desvio" (deviance), mas são ainda compatíveis com o desiderato quineano da unidade fundamental do empreendimento científico, embora, com a admissão de lógicas alternativas à clássica, abrem a possibilidade de não mais considerar a lógica clássica como "metateoria padrão" da ciência ou da própria lógica (v. BACON, 2013). Uma forma ainda mais radical desviar-se, neste ponto, de Quine sem se afastar em demasia do "espírito" quineano, seria considerar que uma lógica, clássica ou não clássica, não seria outra coisa senão uma dada estrutura matemática, passível de ser estudada, em suas propriedades e relações com estruturas semelhantes, com o emprego de arcabouços metateóricos diversos, como pode ser feito na linha da proposta da lógica universal de Béziau, acima descrita. Para tanto, a relatividade linguístico-ontológica se Quine se aprofundaria em algo semelhante à relatividade conceitual proposta por Hilary Putnam (1982), que passaria a contemplar a flexibilidade do próprio aparato lógico, o que aliás se coaduna com a ideia quineana de que a própria lógica se remete a uma linguagem ou esquema conceitual de fundo, acrescentando apenas que estes também seriam passíveis de variação contextual.

Pode-se dizer, portanto, que Quine ajudou a modelar os debates atuais sobre o pluralismo lógico, não só como modelo de oposição a este, mas ainda inspirando certas abordagens pluralistas. Uma abordagem de inspiração quineana deverá, em regra, conceituar o conflito entre lógicas alternativas segundo o modelo do conflito parcial, e corroborar a tese da mudança de lógica como mudança de significado. O êxito, porém, dessas abordagens, é ainda matéria amplamente debatível. 


\section{REFERÊNCIAS}

ALVES, Daniel D. P. (2014). Compromisso Ontológico: objeções e respostas, Compêndio em linha de problemas em filosofia analítica. Lisboa, 2014, p. 1-39.

BACON, Andrew. (2013). Non-classical Metatheory for Non-classical Logics. Journal of Symbolic Logic, 42/1, Abr. 2013, p. 335-355.

BEALL, J. C.; RESTALL, Greg. (2006). Logical pluralism. Oxford: Clarendon, 2006.

BERGER, Alan. (1980). Quine on "Alternative Logics" and Verdict Tables. The Journal of Philosophy: 77/5, 259-277.

BÉZIAU, Jean-Yves. (2006). 13 Questions about Universal Logic: 13 questions to Jean-Yves Béziau, by Linda Eastwood. Bulletin of the Section of Logic: 35/2, 133-150.

BURGESS, John P. (2009). Philosophical Logic. Princeton, New York: Princeton University Press, 2009.

CARNIELLI, Walter; CONIGLIO, Marcelo; GABBAY, Dov M.; GOUVEIA, Paula; SERNADAS, Cristina. (2008). Analysis and Synthesis of Logics: How to Cut and Paste Reasoning Systems. Dordrecht: Springer, 2008.

DA COSTA, Newton C. A. (1980). Ensaio sobre os fundamentos da lógica. 2. ed. São Paulo: HUCITEC, EDUSP, 1980.

DALLA POZZA, Claudio. (2002). “Logiche devianti e logiche substrutturali: aspetti filosofici”,resumo de um seminário apresentado no Departamento de Filosofia, Universidade de Gênova, 2 maio 2002. Disponível em: < http://www.dif.unige.it/epi/con/dallapozza.pdf > Acesso em: 5 jul. 2019.

DUMMETT, Michael. (1978). Truth. In: . Truth and Other Enigmas. Cambridge: Harvard University Press, 1978, pp. 1-24

EPSTEIN, Richard. (2001). Propositional logics: The Semantic Foundations of Logic. 3. ed. Socorro (NM): ARF, 2012.

HAACK, Susan. (1978) Filosofia das Lógicas. Tradução: Cezar Augusto Mortari, Luiz Henrique de Araújo Dutra. São Paulo: UNESP, 2002.

KNEALE, William; KNEALE, Martha. (1971). The Development of Logic. London: Clarendon, 1971.

MACFARLANE, John Gordon. (2000). What Does It Mean to Say that Logic is Formal. Tese de doutorado. University of Pittsburg, 2000. MALINOWSKI, Grzegorz. (1993). A Philosophy of Many-Valued Logic. The Third Logical Value and Beyond. In: LAPOINTE, Sandra; WOLENSKI, Jan; MARION, Mathieu; MISKIEWICZ, Wioletta (Org.) The golden age of polish philosophy: Kazimierz Twardowski's philosophical legacy. Dordrecht: Springer, 2009.

NEGRO, Antonio. (2010). Quine's challenge and Logical Pluralism. Dissertação de mestrado. Universiteit van Amsterdam. Institute for Logic, Language and Computation, 2010.

POTTER, Michael. (2008). The birth of analytical philosophy. In: MORAN, Dermot (Org.). The Routledge Companion to Twentieth Century Philosophy. London, New York: Routledge, 2008.

PRIEST, Graham. (2001). An Introduction to Non-Classical Logic: From If to Is. 2. ed. Cambridge: Cambridge University Press, 2008.

PUTNAM, Hilary. (1982). A Defense of Internal Realism. In Realism with a Human Face. Cambridge (MA): Harvard University Press, 1990, 30-42. 
QUINE, W. V. (1960). Word and Object. 2. ed. Cambridge (MA): MIT Press, 2013.

. (1948). On What There Is. In.: . From a Logical Point of View. New York: Harvard University Press, 1963, p. 1-19. . (1951). Two Dogmas of Empiricism. In.: . From a Logical Point of View. New York: Harvard University Press, 1963, p. 20-46. . (1968). Ontological Relativity. In: . Ontological Relativity and Other Essays. New York: Columbia University Press, 1969, p. 26-66. . (1970). Philosophy of Logic. 2. ed. Cambridge (MA): Harvard University Press, 1986. . (1973). The Roots of Reference. La Salle: Open Court, 1973.

SILVA, Jairo José da. (2007). Filosofias da matemática. São Paulo: UNESP, 2007. 